Article

\title{
Recycling Lead-Zinc Tailings for Cemented Paste Backfill and Stabilisation of Excessive Metal
}

\author{
Zhu Su®, Qiusong Chen *, Qinli Zhang and Deming Zhang \\ School of Resources and Safety Engineering, Central South University, Changsha 410083, China; \\ suzhu16@163.com (Z.S.); zhangqinlicn@126.com (Q.Z.); leo820425@126.com (D.Z.) \\ * Correspondence: qiusong.chen@csu.edu.cn
}

Received: 14 October 2019; Accepted: 16 November 2019; Published: 17 November 2019

\begin{abstract}
This study demonstrates the feasibility of recycling lead-zinc tailing (LZT) as a cemented paste backfill $(\mathrm{CPB})$ by considering the mechanical properties and environmental effects, thus providing an approach for safe and environmentally friendly treatment of LZT. First, the mechanical properties of $\mathrm{CPB}$ samples were tested. When the cement/tailing ratio was 1:6 and the slurry concentration was $70 \%$, the maximum unconfined compressive strength (UCS) of the CPB cured for 28 days reaching $2.05 \mathrm{MPa}$, which could ensure safe mining. Then, the metals with pollution potential in the backfill slurry were investigated through static leaching. Finally, after adding immobilisation materials to stabilise excessive metals, the environmental stability of the $\mathrm{CPB}$ was demonstrated through dynamic leaching and a toxicity characteristic leaching procedure. The results show that the lead leached from the backfill slurry still exceeds the Chinese standard for groundwater quality (GB/T14848-2017 Class III). The addition of $2 \mathrm{mg} / \mathrm{L}$ polyaluminium sulfate (PAS) can further improve the strength of the $\mathrm{CPB}$ and maintain the environmental friendliness of the $\mathrm{CPB}$. Therefore, the technology of recovering LZT as a CPB proposed in this study is an effective alternative to deal with LZT, which can help lead-zinc mines meet the requirements of cleaner production.
\end{abstract}

Keywords: lead-zinc tailings; cemented paste backfill; immobilisation materials

\section{Introduction}

Lead and zinc resources are abundant in China, and the total output of lead and zinc ranks first in the world. Lead and zinc are widely used in the chemical, light, electrical, machinery, military, and pharmaceutical industries [1]. In addition, lead also has uses in new nuclear and petroleum industries. However, the current development of the lead and zinc industry faces a prominent bottleneck, which is the contradiction between the continuous mining of lead and zinc and the protection of the ecological environment [2]. Large-scale mining of lead and zinc will inevitably produce a large amount of tailing. In China, lead-zinc mines have more poor ores and fewer rich ores and are often associated with heavy metals, such as cadmium, nickel, and arsenic. In addition, incompletely separated lead and zinc are left in the tailings [3]. These toxic heavy metals pose a great threat to the ecological environment. At present, many lead-zinc mines in China still discharge tailings into tailing ponds, which will cause two very severe problems: one is that the solid tailings and tailing slurry will seriously pollute the soil and water system around the reservoir area, and the other is that tailing ponds will face the risk of a dam break with the accumulation of tailings [4].

In recent years, the backfill mining method, which fills the stope with tailings as filling material, has been greatly developed in China [5]. Several scholars have investigated the types of backfill materials along with the backfilling process [6,7]. The goal of recycling lead-zinc tailing (LZT) as cemented paste backfill (CPB) is to eliminate two current major problems faced by lead-zinc mining: 
specifically, (1) the instability of the mine in the mining process [8-13]; and (2) the ecological damage caused by the accumulation of tailings.

In view of the first problem, the study focuses on whether the strength of the CPB can meet the requirements of safe underground mining. Backfill materials are subject to load conditions [14,15]. Because they are small and have no agglomeration, the tailings are only fillers in the CPB [16]. To meet reasonable strength requirements, it is necessary to obtain the optimum ratio of binder. In general, Portland cement is often used as the main binder, but some studies have also confirmed that fly ash, slag, and superplasticisers can substitute part of the Portland cement to improve the performance of CPB $[17,18]$. The optimum cementing ratio must consider two factors comprehensively: one is to meet the suitable strength of safe mining, and the other is to save cement consumption as much as possible and reduce the economic cost of mining under the premise of safe mining.

In view of the second problem, the study focuses on whether the tailings will further pollute the underground environment after recycling as part of the $\mathrm{CPB}$. Many studies have pointed out that the surface accumulation of LZT will release numerous toxic heavy metal elements, such as mercury, lead, and cadmium [19-21]. Whether these elements will continue to dissolve after the CPB is filled in the stope requires further testing and verification. If it is determined that the heavy metals leached from the $\mathrm{CPB}$ during setting will still pollute the underground environment, the next research topic will be how to stabilise these heavy metals with pollution risk to keep the CPB environmentally friendly.

The purpose of this study is to develop a safe and environmentally friendly way to recover LZT, which will be recycled as a CPB in the laboratory. The fluidity and mechanical properties of the $\mathrm{CPB}$ will be determined using slump and unconfined compressive strength (UCS) tests, respectively. In addition, to meet the needs of protecting the underground ecological environment, this study will also discuss the chemical toxicity of the CPB, detect harmful heavy metals in the backfill slurry, and explore a stabilisation method to avoid the release of heavy metals.

\section{Materials and Methods}

\subsection{Test Materials}

\subsubsection{Lead-Zinc Tailing}

The LZT used in this study was taken from the Luoba lead-zinc mine in Gansu, China. The sampling position and process are shown in Figure 1. The specific sampling process at the site was as follows: (1) tailing slurry was collected using a filter cloth made into a container, and then low-concentration tailing slurry was poured into it; (2) regarding concentration and dewatering, the low-concentration tailing slurry was filtered using a filter cloth and was evaporated naturally to obtain a high-concentration tailing slurry. After the on-site sampling was completed, the high-concentration tailing slurry was transported to the laboratory of Central South University, China. The process of obtaining samples in the laboratory was as follows: the agglomerated tailings were chopped and sent to the oven for drying; the drying temperature was $55^{\circ} \mathrm{C}$, and the drying time was $10 \mathrm{~h}$; due to the natural sedimentation of the tailing slurry during the sampling process and the agglomeration of some tailings during the drying process, the tailings were sieved and mixed.

At the same time, a small amount of the original low-concentration tailing slurry was also transported to the laboratory and dried under the same conditions as the LZT samples.

The major elemental composition of LZT samples and raw LZT was determined using a Philips MagiX PRO XR spectrometer (X-ray fluorescence; Amsterdam, The Netherlands). Table 1 shows that LZT samples represent the conditions of raw LZT on site.

The chemical composition of LZT was determined using X-ray diffraction (D8 Advance Diffractometer, Bruker AXS; Karlsruhe, Germany). As shown in Table 2, the main chemical components of $\mathrm{LZT}$ are $\mathrm{SiO}_{2}$ and $\mathrm{CaO}$, which are beneficial to the strength development of the CPB [22]. The particle size distribution of LZT was measured using a Mastersizer 2000 particle size analyser (Malvern Instruments Ltd; Malvern, UK). The test results are shown in Figure 2. The physical properties of 
LZT are shown in Table 3. Because the median particle size is only $0.0281 \mathrm{~mm}$ and the proportion of particles smaller than $0.020 \mathrm{~mm}$ is $44.09 \%$, LZT can be classified as medium tailings [23], which may have adverse effects on the strength development of the CPB [24]. The coefficient of uniformity $(\mathrm{Cu})$ of LZT is greater than 12 , and the coefficient of curvature $\left(C_{c}\right)$ is less than 1 , which indicates that LZT belongs to gap-graded aggregate [25]. When gap-graded aggregate is used as a backfill material, it will also cause slight adverse effects on the strength development of the CPB [26].

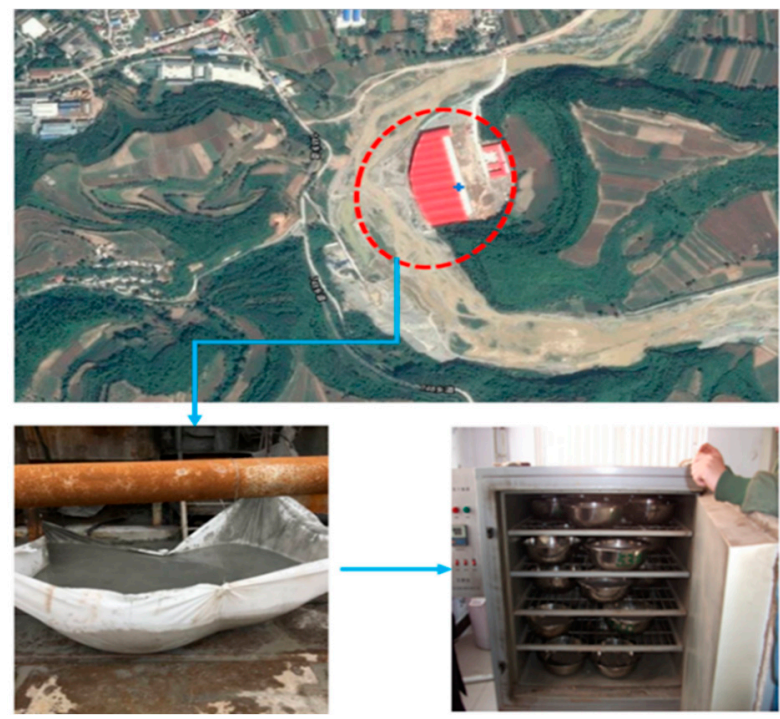

Figure 1. Sampling location and sampling process.

Table 1. Comparison of elemental composition between lead-zinc tailing (LZT) samples and raw LZT (wt \%).

\begin{tabular}{ccccccccccccc}
\hline Elements & $\mathbf{O}$ & $\mathbf{S i}$ & $\mathbf{S}$ & $\mathbf{F e}$ & $\mathbf{C r}$ & $\mathbf{C u}$ & $\mathbf{Z n}$ & $\mathbf{P b}$ & $\mathbf{N i}$ & $\mathbf{A s}$ & $\mathbf{C a}$ & $\mathbf{K}$ \\
\hline LZT samples & 36.8 & 16.04 & 1.1 & 11.54 & 0.015 & 0.012 & 0.25 & 0.2 & 0.01 & 0.018 & 19.04 & 0.925 \\
Raw LZT & 37.2 & 16.93 & 1.02 & 11.32 & 0.016 & 0.011 & 0.26 & 0.2 & 0.01 & 0.02 & 18.83 & 0.912 \\
\hline
\end{tabular}

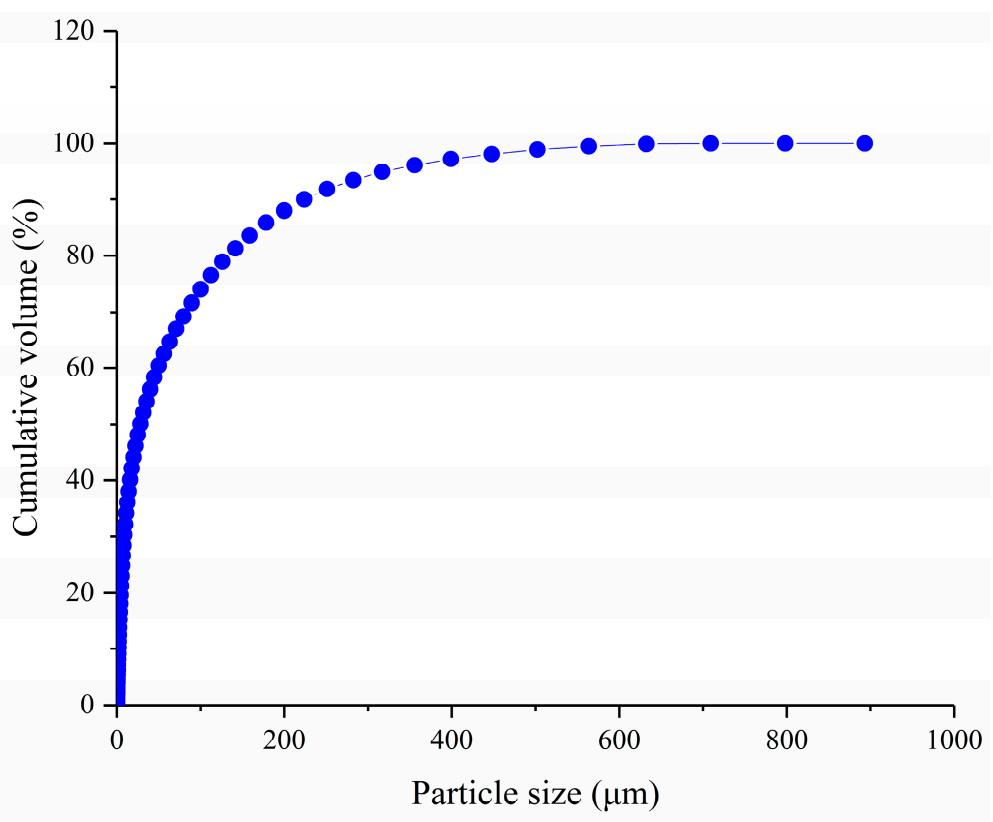

Figure 2. Particle size distribution of lead-zinc tailing (LZT). 
Table 2. Chemical composition of lead-zinc tailing (LZT) (wt\%).

\begin{tabular}{cccccccc}
\hline $\mathrm{CaO}$ & $\mathrm{SiO}_{2}$ & $\mathrm{Fe}_{2} \mathrm{O}_{3}$ & $\mathrm{Al}_{2} \mathrm{O}_{3}$ & $\mathrm{MgO}$ & $\mathrm{K}_{2} \mathrm{O}$ & $\mathrm{ZnO}$ & $\mathrm{PbO}$ \\
\hline 28.23 & 35.63 & 16.28 & 7.33 & 1.23 & 1.13 & 0.32 & 0.23 \\
\hline
\end{tabular}

Table 3. Physical properties of lead-zinc tailing (LZT).

\begin{tabular}{cccccccc}
\hline $\begin{array}{c}\text { Physical } \\
\text { Properties }\end{array}$ & Gs & $\mathbf{d}_{\mathbf{6 0}}(\mu \mathrm{m})$ & $\mathbf{d}_{\mathbf{5 0}}(\mu \mathrm{m})$ & $\mathbf{d}_{\mathbf{3 0}}(\mu \mathrm{m})$ & $\mathbf{d}_{\mathbf{1 0}}(\mu \mathrm{m})$ & $\mathbf{C u}$ & Cc \\
\hline LZT & 2.94 & 50.18 & 28.077 & 8.83 & 1.963 & 25.56 & 0.79 \\
\hline
\end{tabular}

\subsubsection{Binders}

The binder used in this study was No.325 Portland cement, which was produced according to the common Portland cement standard of China [27]. Table 4 summarises the chemical compositions and physical properties of cement. The water used for static leaching was groundwater from the Luoba mining area, which was collected in sealed drums and transported to the laboratory of Central South University, China.

Table 4. The physical properties of cement.

\begin{tabular}{cc}
\hline \multicolumn{3}{c}{ Chemical Composition (\%) } \\
\hline $\mathrm{CaO}$ & 63.62 \\
$\mathrm{SiO}_{2}$ & 20.13 \\
$\mathrm{Al}_{2} \mathrm{O}_{3}$ & 4.78 \\
$\mathrm{Fe}_{2} \mathrm{O}_{3}$ & 3.97 \\
$\mathrm{MgO}$ & 1.46 \\
$\mathrm{~K}_{2} \mathrm{O}$ & 0.61 \\
$\mathrm{TiO}_{2}$ & 0.31 \\
$\mathrm{LOI}$ & 4.12 \\
\hline \multicolumn{2}{c}{ Physical Properties } \\
\hline $\mathrm{d}_{50}(\mu \mathrm{m})$ & 14.69 \\
$\mathrm{~d}_{90}(\mu \mathrm{m})$ & 40 \\
$\mathrm{~d}_{[4,3]}(\mu \mathrm{m})$ & 18.3 \\
$\rho\left(\mathrm{g} / \mathrm{cm}_{3}\right)$ & 3.08 \\
\hline
\end{tabular}

\subsection{Test Methods}

\subsubsection{Cemented Paste Backfill Sample Preparation}

The LZT, binders and water were mixed into 15 groups of slurries with different proportions. The cement/tailing ratios were 1:6, 1:8, 1:10, 1:15, and 1:20, and the mass concentration was $68 \%, 70 \%$ and $72 \%$. The slurry was poured into the mixer at a speed of $200 \mathrm{r} / \mathrm{min}$ for mixing, and then the slurry was cast into the plastic mould with an internal size of $70.7 \mathrm{~mm} \times 70.7 \mathrm{~mm} \times 70.7 \mathrm{~mm}$. After the initial setting of the slurry, the excess material on the surface of the mould was scraped with a shovel [28]. Finally, the samples were taken out of the mould after $24 \mathrm{~h}$ of setting and were placed in a curing box (YH -40B, Qingda, Tianjin of China) with constant temperature and humidity $\left(20 \pm 2{ }^{\circ} \mathrm{C}\right.$ and $90 \% \pm 5 \%$, respectively).

\subsubsection{Slurry Fluidity Test}

Slurry fluidity was measured using a slump test [29]. The concrete operation was to place the conical slump cylinder (300 $\mathrm{mm}$ in height, $100 \mathrm{~mm}$ in diameter at the top, and $200 \mathrm{~mm}$ in diameter at the bottom) on the flat surface and press down tightly, then pour the stirred backfill slurry into the cylinder. After the slurry was filled with the slump cylinder, the slump cylinder was lifted steadily 
and vertically, and the process should be completed within 5-10 s. The slump cylinder was placed beside the slurry after lifting, and the vertical distance between the highest point of slurry and the top of the cylinder (in $\mathrm{mm}$, accurate to $5 \mathrm{~mm}$ ) was measured, which was the slump of the backfill slurry. The whole process from the start of loading to the end of lifting was completed in $150 \mathrm{~s}$ [30].

\subsubsection{Unconfined Compressive Strength Test}

In the mining process, $\mathrm{CPB}$ must meet the appropriate strength requirements, and different mines determine the minimum compressive strength of $\mathrm{CPB}$ according to actual production needs. The UCS of $\mathrm{CPB}$ samples were cured for 7, 14, and 28 days and were measured using a WDW-2000 rigid hydraulic pressure servo machine (Ruite, Guilin, China). The displacement rate of the machine load was $0.5 \mathrm{~mm} / \mathrm{min}$ per minute [31]. Each test was repeated three times, and the average was used for further analysis.

\subsubsection{Static Leaching}

The static leaching test was conducted by adding a mixture of $90 \mathrm{~g}$ of LZT and $15 \mathrm{~g}$ of cement into $400 \mathrm{~mL}$ of groundwater, and the comparative leaching test was conducted by adding $90 \mathrm{~g}$ of LZT to $400 \mathrm{~mL}$ of groundwater. The leachate samples of both groups were fully stirred by centrifuge at first, then filtered with a 0.45-um filter at different time intervals within $48 \mathrm{~h}$, and the leachate was collected for chemical analysis.

\subsubsection{Stabilisation Test of Excessive Elements}

The excessive elements could be further stabilised by adding corresponding immobilisation materials. The methods of stabilising excessive elements included chemical precipitation [32], coagulation precipitation, ion exchange [33] and adsorption. When the coagulation precipitation process was used to treat excessive elements, the dosage of coagulant was not much, but the precipitation speed was fast. At the same time, this process could adapt to a wide range of $\mathrm{pH}$ values, and the effect was obvious. The coagulation precipitation process was widely used in the stabilisation test [34].

The results of the static leaching test show that the leaching concentration of lead in the early setting of backfill samples does not meet the environmental standard of groundwater in China. Some scholars have pointed out that polyaluminium salt has a good stabilising effect on metal ions [35], and the commonly used polyaluminium salts include polyaluminium chloride (PAC) and polyaluminium sulfate (PAS). Yuan et al. [36] demonstrated that PAS had a better stabilisation effect on lead than PAC, which would be designed for the stabilisation test for lead in this study.

The PAS with concentrations of $1 \mathrm{mg} / \mathrm{L}, 2 \mathrm{mg} / \mathrm{L}, 2.5 \mathrm{mg} / \mathrm{L}, 3 \mathrm{mg} / \mathrm{L}$, and $4 \mathrm{mg} / \mathrm{L}$ were added to the CPB slurry with the optimal ratio (cement/tailing ratio $1: 6$, slurry concentration $70 \%$ ), which was determined in the previous test. The bleeding of each slurry after $24 \mathrm{~h}$ of setting was collected and filtered through a $0.45-\mu \mathrm{m}$ filter for the detection of lead concentration.

\subsubsection{Dynamic Leaching and Strength Retest}

To investigate the strength change and environmental stability of the CPB after adding immobilisation materials to remove excessive elements, the UCS of the CPB samples with a curing age of 7, 14, and 28 days after adding immobilisation materials was measured, and then the samples were crushed into ash to maintain the same appearance as the LZT. The ash samples of different ages were dried at room temperature and screened with a 200-um screen, $10 \mathrm{~g}$ of which was added into $100 \mathrm{~mL}$ of deionised water, and then soaked in an incubator at $20^{\circ} \mathrm{C}$ for $24 \mathrm{~h}$. Moreover, $10 \mathrm{~mL}$ of the leachate was filtered through a $0.45-\mu \mathrm{m}$ filter after $24 \mathrm{~h}$, which was divided into two portions, one was acidified with $0.1 \mathrm{~mL}$ of $1+1$ nitric acid $\left(\mathrm{HNO}_{3}\right)$ solution for the ICP test, and the other for $\mathrm{pH}$ and conductivity detection. After the leachate was extracted, deionised water was added to the ash again, maintaining a solid-liquid ratio of 1:10. The leaching process was repeated five times to imitate the leaching of elements at different curing ages after the CPB is filled into the stope. 


\subsubsection{Toxicity Characteristic Leaching Procedure}

The toxicity characteristic leaching procedure (TCLP) is the most commonly used toxicity characteristic leaching test, and the evaluation method of the release potential of heavy metals is recommended by the US Environmental Protection Agency (EPA). This test can simulate the process of metal elements permeating into groundwater after the CPB is filled into the stope $[37,38]$. The CPB samples of different curing ages were ground and sieved into ash of less than $9.5 \mathrm{~mm}$ in diameter. The ash was added to a $0.1 \mathrm{~N}$ acetic acid solution at a solid-liquid ratio of 1:20 and then was immersed in a rotary oscillator at a speed of $30 \pm 2 \mathrm{rpm}$ for $18 \mathrm{~h}$. The leachate was filtered through a $0.45-\mu \mathrm{m}$ filter after $18 \mathrm{~h}$ and was acidified with $0.1 \mathrm{~mL}$ of $1+1 \mathrm{HNO}_{3}$ solution for the ICP test.

\subsubsection{Chemical Measurement}

The $\mathrm{pH}$ was measured using a $\mathrm{pH}$ meter (HSCAN $20 \mathrm{~S}, \pm 0.01$, China). The conductivity was measured using a conductivity meter (ST20C, OHAUS, China). The metal element content was measured using inductively coupled plasma-atomic emission spectrometry (ICP-AES; Baird, PS-6, USA).

\section{Results and Discussion}

\subsection{Feasibility of CPB Pipeline Transportation}

The CPB slurry was prepared on the ground and then transported to the underground through the pipeline during the production process in the mine site. The premise of determining slurry concentration was that slurry fluidity met the requirements of pipeline transportation. Previous studies have indicated that the CPB slurry with a slump value of 190 to $270 \mathrm{~mm}$ can be piped to the stope via gravity or pumping [39]. The variation of the slump of the slurry with different concentrations is shown in Figure 3. The slump decreases with the slurry concentration increasing from $68 \%$ to $78 \%$. When the slurry concentration exceeds $74 \%$, the slump is less than $190 \mathrm{~mm}$. At this time, the slurry does not have good fluidity, which may lead to blockage of the transportation pipeline.

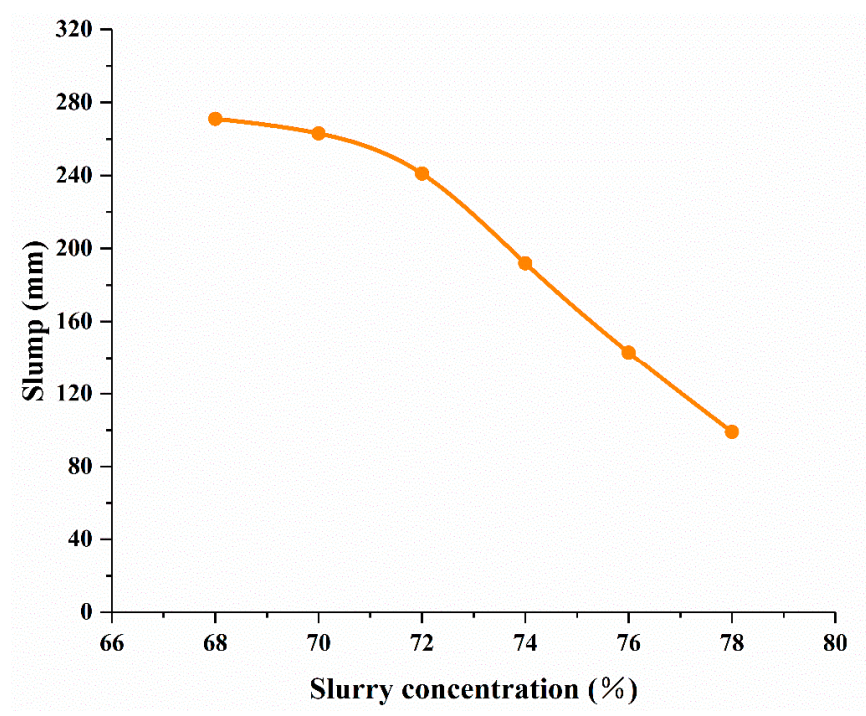

Figure 3. Variation of the slump of the cemented paste backfill (CPB) slurry with different concentrations.

\subsection{UCS Test Results}

The UCS test result is the primary parameter for the design of the backfill system in the mine, which is an important basis for evaluating the support performance of the CPB in the stope [40]. The UCS values of 15 groups of CPB samples with different cement/tailing ratios and mass concentrations are 
shown in Figure 4 after curing for 7, 14, and 28 days. Previous studies have pointed out that slurry concentration is an important factor affecting CPB strength [41]. The figure illustrates that the UCS value increases with the increase of slurry concentration under the same cement/tailing ratio. When the slurry concentration is $72 \%$, the measured strength is the largest, which confirms that the slurry concentration can significantly affect the strength of the CPB. When the cement/tailing ratio is $1: 6$, and the slurry concentration is $72 \%$, the maximum UCS value of CPB samples is $2.5 \mathrm{MPa}$ at 28 days of curing. In summary, the strength of the CPB mainly depends on the hydration process of the cement in the slurry [42]. The LZT itself does not have cementation. According to the USC test results, synthetically considering the actual production needs and economic costs of the mine, the optimal $\mathrm{CPB}$ ratio is determined as the cement/tailing ratio of $1: 6$ and a slurry concentration of $70 \%$.

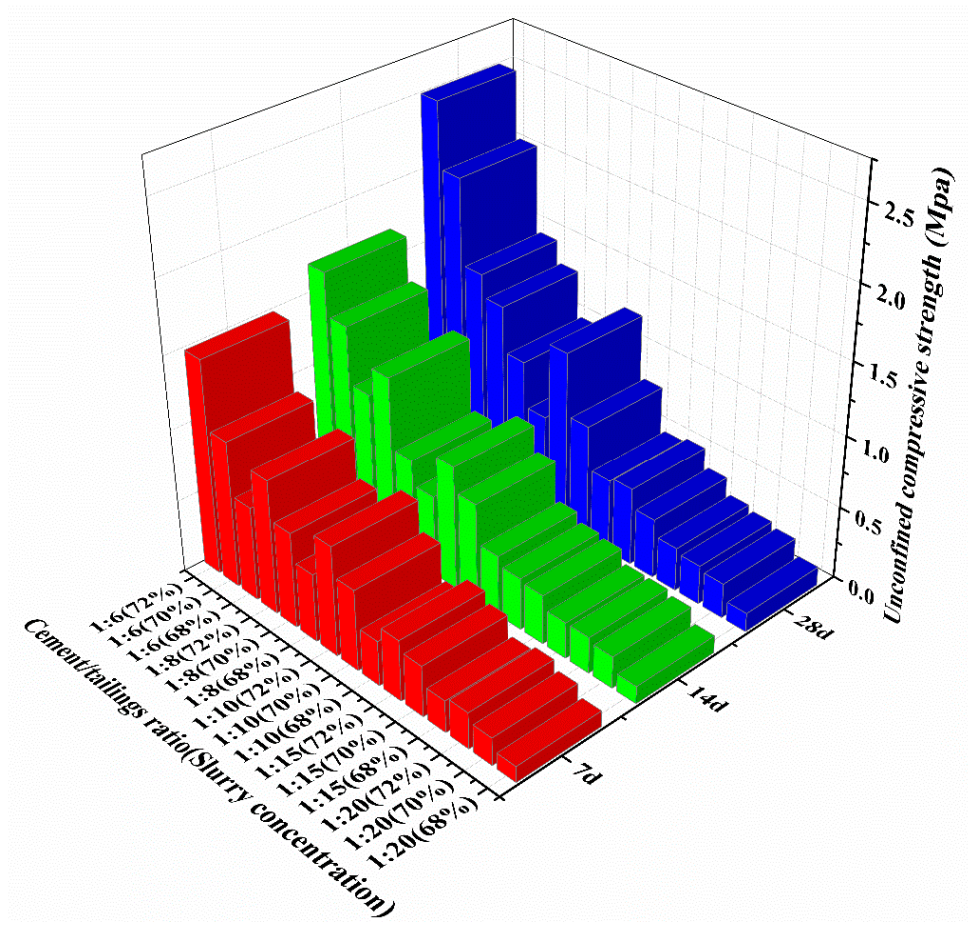

Figure 4. Unconfined compressive strength evolution with different cement/tailing ratios (slurry concentrations).

\subsection{Determination of Excessive Metal Elements by Static Leaching}

Although the hydration process of cement will produce a certain mechanical strength, the heavy metals contained in the LZT still have the risk of contaminating groundwater. To investigate the leaching characteristics of heavy metals in the backfill slurry after transporting it underground, the concentration of heavy metals in the leachate of LZT and backfill samples was monitored during the first $48 \mathrm{~h}$ of static leaching. The $\mathrm{pH}$ of the leachate was measured at the beginning and end of the monitoring. The $\mathrm{pH}$ value of the leachate of LZT changed from 8.1 to 9.2, and that of the backfill samples changed from 11.5 to 12.9 .

The variation of lead concentration in the leachate of LZT and backfill samples with time is shown in Figure 5. Lead is sourced from the residue of lead-zinc ore in the process of beneficiation, which will infiltrate the surrounding environment and does great harm to nature and humans. The figure shows that the concentration of lead in the leachate of backfill samples is higher than that in the leachate of LZT in the first two hours, which may be caused by the increase in $\mathrm{pH}$ in the soaking solution of the backfill samples after the addition of the alkaline cement. In a strong alkaline solution, the hydroxide formula of lead can be expressed by $\mathrm{H}_{2} \mathrm{PbO}_{2}$, which is acid-ionised by $\mathrm{OH}^{-}$ions in water, and lead mainly exists in the form of $\mathrm{HPbO}_{2}{ }^{-}$at this time. The specific chemical reaction follows:

$$
\mathrm{H}_{2} \mathrm{PbO}_{2} \rightleftharpoons \mathrm{HPbO}_{2}^{-}+\mathrm{H}^{+}
$$


After $2 \mathrm{~h}$, the lead concentration in the leachate of the backfill samples gradually decreased, which was due to the adsorption of the calcium silicate hydrate (C-S-H) gel generated by cement hydration process. The leaching concentration of lead gradually became steady after $30 \mathrm{~h}$, and the measured concentration of lead at $48 \mathrm{~h}$ was $0.3 \mathrm{mg} / \mathrm{L}$. According to the Chinese national standard (class III) [43] for groundwater quality, the concentration of lead should be less than $0.01 \mathrm{mg} / \mathrm{L}$, so there is still a risk of groundwater pollution.

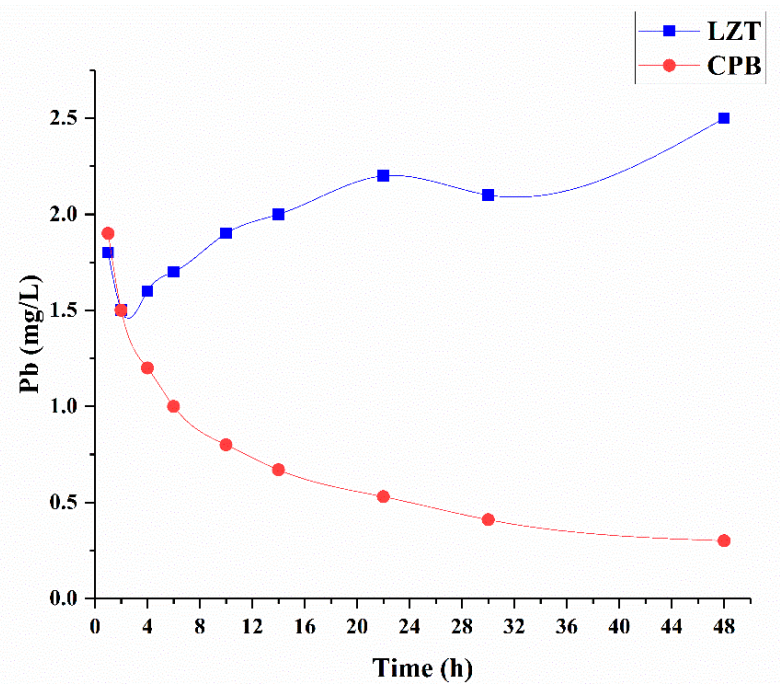

Figure 5. Lead $(\mathrm{Pb})$ concentration in static leachate of lead-zinc tailing (LZT) and backfill samples.

At the same time, the residual zinc in the beneficiation process of lead-zinc ore was also monitored. Figure 6 illustrates that the zinc concentration in the leachate of LZT remains relatively stable because the LZT soaking solution is weakly alkaline. When the $\mathrm{pH}$ is in the range of 7.5 to 10 , zinc mainly exists in the form of precipitation [44], so the zinc concentration only increases slightly with time. The zinc concentration in the leachate of backfill samples tends to increase in the first two hours, which may be caused by the rapid increase of alkalinity in the soaking solution after adding cement. At this time, zinc exists in two forms, $\left[\mathrm{Zn}(\mathrm{OH})_{3}\right]^{-}$and $\left[\mathrm{Zn}(\mathrm{OH})_{4}\right]^{2-}$, in the leachate. In the later stage, with the hydration of the cement, the zinc concentration in the leachate of the backfill samples decreased rapidly. After $30 \mathrm{~h}$, the leaching concentration of the zinc tended to be steady and far less than the standard of $1.0 \mathrm{mg} / \mathrm{L}$ in GB.

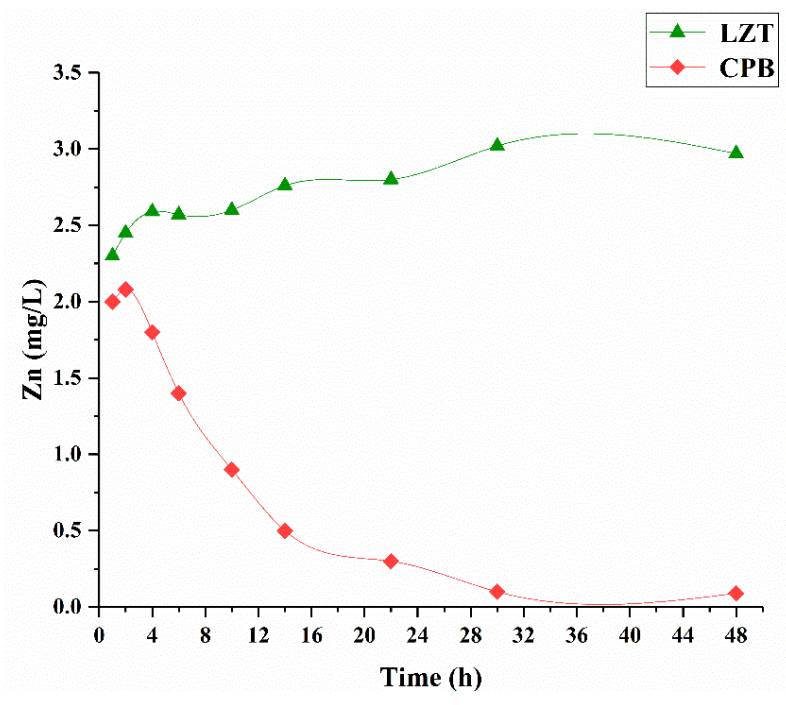

Figure 6. Zinc (Zn) concentration in static leachate of lead-zinc tailing (LZT) and backfill samples. 
The concentration of other monitored heavy metal elements was also measured after $48 \mathrm{~h}$. The concentrations of iron, chromium, arsenic, copper, and nickel were measured in the leachate of the LZT and backfill samples and are listed in Table 5. The table shows that the leaching concentration of metals in the leachate of the backfill samples decreased significantly due to the addition of the cementitious agent. After $48 \mathrm{~h}$, the concentration of all heavy metals monitored in the leachate of the backfill samples was lower than the GB standard.

Table 5. Metal concentrations in the static leachate of lead-zinc tailing (LZT) and backfill samples after $48 \mathrm{~h}$.

\begin{tabular}{cccc}
\hline Parameters & LZT $(\mathbf{m g} / \mathbf{L})$ & Backfill $(\mathbf{m g} / \mathbf{L})$ & GB Standard $(\mathbf{m g} / \mathbf{L})$ \\
\hline $\mathrm{Fe}$ & 30.2 & 0.2 & 0.3 \\
$\mathrm{Cr}$ & 0.4 & $<0.02$ & 0.05 \\
$\mathrm{As}$ & 0.3 & 0.003 & 0.01 \\
$\mathrm{Cu}$ & 0.3 & $<0.001$ & 1 \\
$\mathrm{Ni}$ & 0.1 & 0.008 & 0.02 \\
\hline
\end{tabular}

\subsection{Optimum Dosage of Immobilisation Materials}

The results of the lead concentration measurement in the bleeding of the CPB slurry after the addition of the immobilisation materials are shown in Figure 7. When the PAS concentration is less than $2 \mathrm{mg} / \mathrm{L}$, the lead concentration in the bleeding gradually decreases with the increase of PAS dosage, which confirms that PAS has a good stabilisation effect on lead. The reason for this phenomenon may be that PAS has excellent water-decomposing performance. When PAS dissolves in neutral or slightly alkaline water, a colloidal precipitation $\mathrm{A} 1(\mathrm{OH})_{3}$ is formed, which causes coagulation and adsorbs the lead in the solution. In addition, the figure shows that the removal rate of lead is the highest when the dosage range of PAS is $2-3 \mathrm{mg} / \mathrm{L}$, and the concentration of lead in the bleeding is less than the GB standard when the dosage of PAS is $2 \mathrm{mg} / \mathrm{L}$.

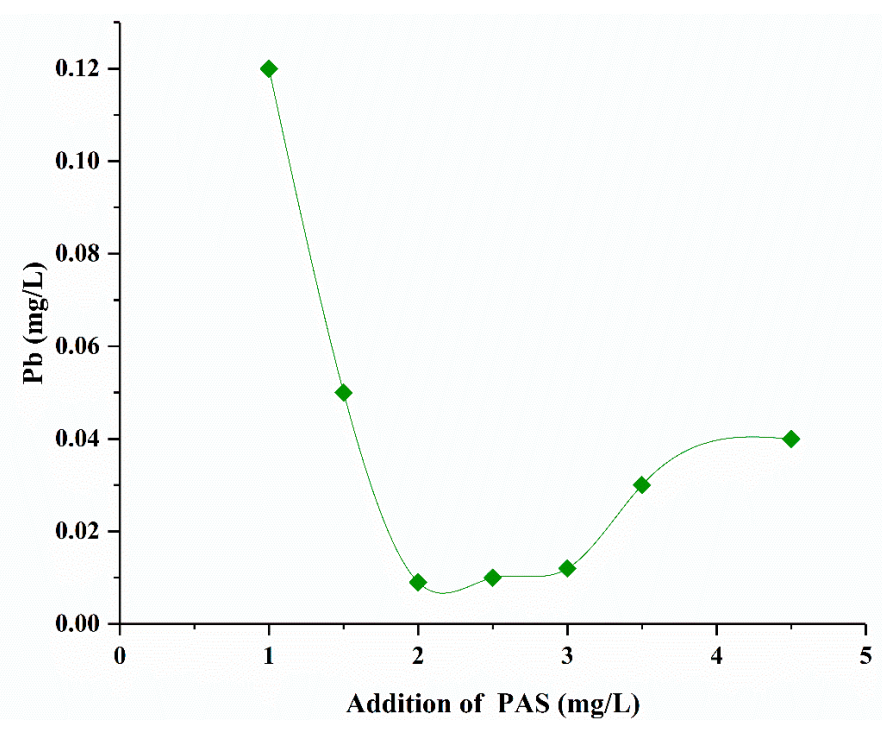

Figure 7. Lead $(\mathrm{Pb})$ concentration in bleeding after $24 \mathrm{~h}$ of pre-setting.

\subsection{UCS Retest Results and Environmental Effects of CPB after the Addition of Immobilisation Materials}

\subsubsection{UCS Comparison}

The strength of the $\mathrm{CPB}$ at different curing ages after the addition of the immobilisation materials was compared to the original strength. The UCS value of the CPB after adding $2 \mathrm{mg} / \mathrm{L}$ PAS is about $9 \%$ to $13 \%$ higher than the original UCS value from Table 6 , which may because aluminium 
sulfate accelerates the hydration of tricalcium silicate $\left(\mathrm{C}_{3} \mathrm{~S}\right)$, thus increasing the strength of the cement paste [45]. Therefore, the addition of immobilisation materials will not adversely affect the strength of the $\mathrm{CPB}$ and can further ensure the strength requirements of safe mining.

Table 6. Unconfined compressive strength (UCS) variation of cemented paste backfill (CPB) samples with a cement/tailing ratio of $1: 6$ and slurry concentration of $72 \%$.

\begin{tabular}{ccc}
\hline Curing Age & Original UCS Value (MPa) & UCS Value after Adding Immobilisation Materials (MPa) \\
\hline 7 days & 1.02 & 1.15 \\
14 days & 1.41 & 1.56 \\
28 days & 2.06 & 2.24 \\
\hline
\end{tabular}

\subsubsection{Environmental Stability of the CPB in Dynamic Leaching}

To investigate the leaching characteristics of elements from the CPB in underground stope after adding $2 \mathrm{mg} / \mathrm{L}$ PAS, five-round dynamic leaching tests were conducted on CPB samples with a curing age of 7,14 , and 28 days. The dynamic leaching procedure can simulate the underground infiltration conditions under a natural environment [46].

The metal concentrations in the five-round dynamic leaching tests of the LZT were measured as shown in Figure 8. The concentration of metal ions in the first round of leaching dominates the five-round dynamic leaching, which indicates that the metal ions in LZT migrate easily with rainwater in the natural environment, reflecting that LZT has enormous environmental hazards if directly discharged into the natural environment without any treatment. The metal concentration of the five-round dynamic leaching tests of $\mathrm{CPB}$ samples with a curing age of 7 days was measured as shown in Figure 9. The leaching concentration of metal ions in CPB is quite low due to the addition of binder and immobilisation materials, which proves that they are well immobilised in the CPB. The leaching concentration of metal ions in each round satisfies the GB standard.

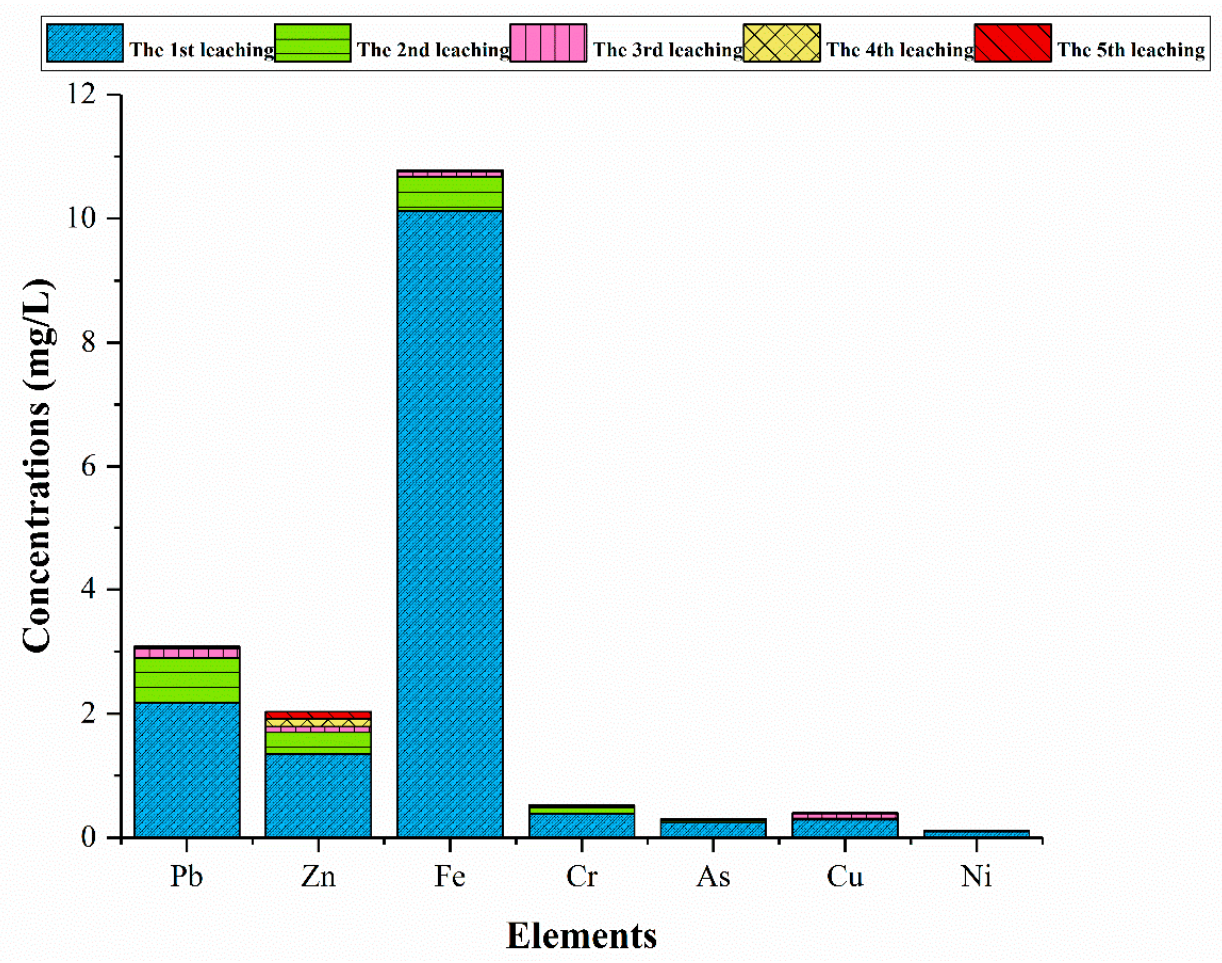

Figure 8. Concentration of metal ions in dynamic leaching of lead-zinc tailing (LZT). 


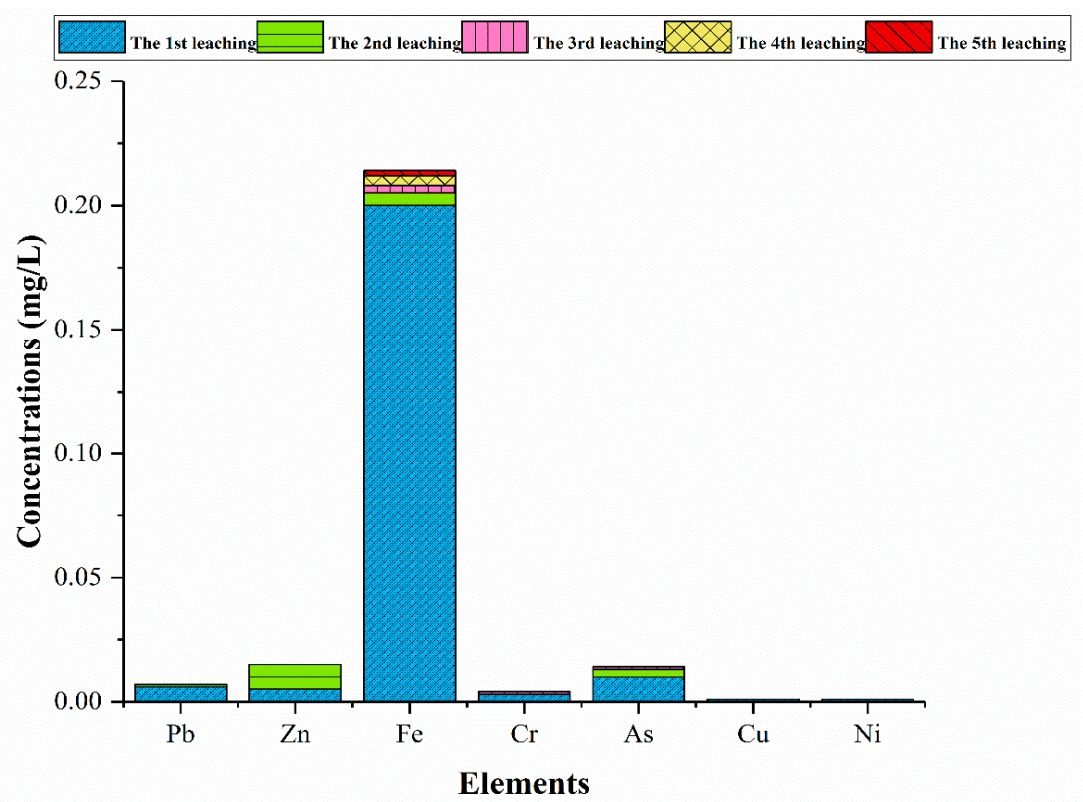

Figure 9. Concentration of metal ions in dynamic leaching of cemented paste backfill (CPB) samples.

As shown in Figure 10, the leachate pH of CPB samples is obviously higher than that of LZT leachate, which is due to the alkalinity of the cement. The leachate $\mathrm{pH}$ of the CPB samples with curing age of 7 days and 14 days is significantly higher than that of CPB samples with a curing age of 28 days, which may be due to the continuous formation of $\mathrm{OH}^{-}$during the hydration process of the cement. In addition, the figure shows that the leachate conductivity of the CPB samples with a curing age of 7 days and 14 days has been declining, which also proves the continuity of the cement hydration process. The decrease in conductivity reflects the decrease of leaching ions, which is caused by two factors. One is the precipitation of some metal ions combined with $\mathrm{OH}^{-}$, and the other is the adsorption of a large number of ions by C-S-H gel produced by cement hydration. The leachate $\mathrm{pH}$ of the CPB samples with a curing age of 28 days remained relatively stable during the five rounds of dynamic leaching, concentrated in the range of 10.73 to 11.21 , and the leachate conductivity also remained stable, which indicated that the hydration process of cement had been basically completed.

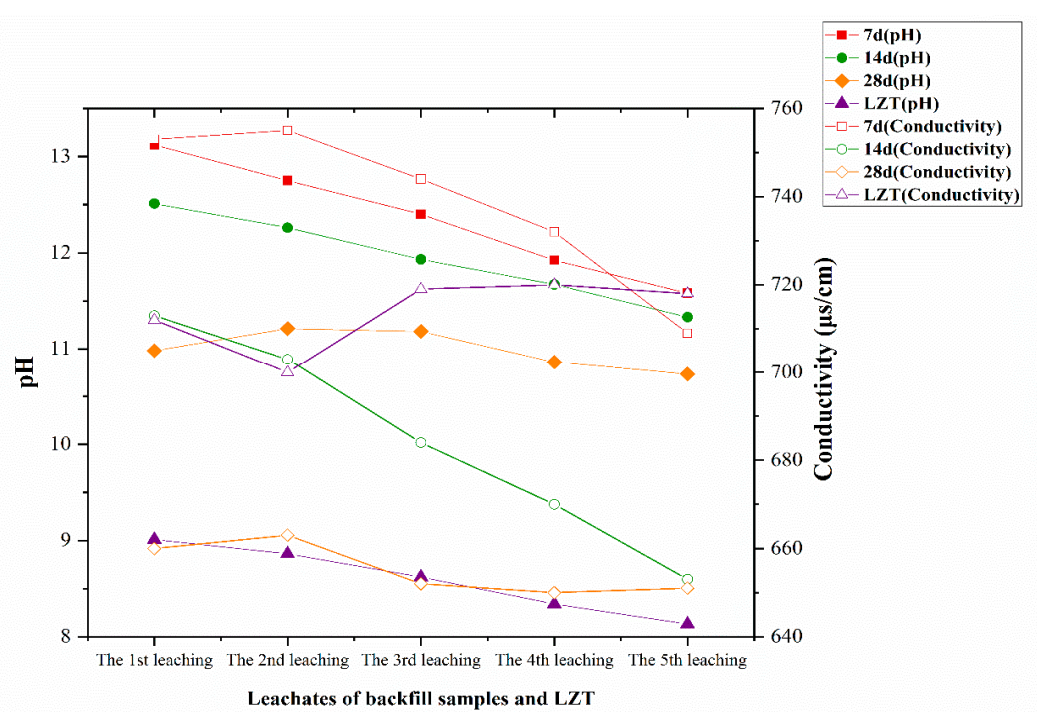

Figure 10. Changes in $\mathrm{pH}$ and conductivity in dynamic leaching. 


\subsubsection{Environmental Evolution by TCLP}

The TCLP extractable metals in LZT and CPB samples are presented in Table 7. The extractable concentration of metals in CPB samples is much lower than that in LZT. The concentrations of lead, zinc, iron, chromium, arsenic, copper, and nickel extracted by the $\mathrm{CPB}$ samples all meet the GB standard, which reflects that the concentration of heavy metals leaching from the CPB will not pollute the groundwater after the $\mathrm{CPB}$ is filled into the underground stope.

Table 7. Element concentration in toxicity characteristic leaching procedure (TCLP).

\begin{tabular}{ccccccccc}
\hline \multirow{2}{*}{ Samples } & \multicolumn{7}{c}{ Elements $(\mathbf{m g} / \mathbf{L})$} \\
\cline { 2 - 8 } & $\mathbf{P b}$ & $\mathbf{Z n}$ & $\mathbf{F e}$ & $\mathbf{C r}$ & $\mathbf{A s}$ & $\mathbf{C u}$ & $\mathbf{N i}$ \\
\hline LZT & 0.08 & 0.05 & 3.1 & 0.01 & 0.01 & 0.02 & $<0.001$ \\
CPB curing for 7 days & 0.006 & 0.003 & 0.04 & $<0.001$ & 0.001 & $<0.001$ & $<0.001$ \\
CPB curing for 14 days & 0.005 & 0.005 & 0.02 & $<0.001$ & $<0.001$ & $<0.001$ & $<0.001$ \\
CPB curing for 28 days & 0.001 & 0.002 & 0.03 & $<0.001$ & $<0.001$ & $<0.001$ & $<0.001$ \\
GB standard & 0.01 & 1 & 0.3 & 0.05 & 0.01 & 1 & 0.02 \\
\hline
\end{tabular}

In conclusion, the dynamic leaching test and the TCLP verify that the leaching capacity of the heavy metal ions in the $\mathrm{CPB}$ can be effectively controlled, which has favourable environmental benefits.

\section{Discussion}

\subsection{Potential of Significant Reuse of LZT as Backfill Material}

As China attaches increased importance to the high-quality development of the economy, environmental protection issues in the mineral development process have become increasingly stringent. The main purpose of this study is to investigate the possibility of recycling LZT in a safe and environmentally friendly manner, which would help in reusing a significant amount of the produced LZT. The current work shows that LZT can be used as the main material for mine backfilling, which accounts for $86 \%$ of the total solid content of the CPB. The cement/tailing ratio is an important factor affecting the strength of the $\mathrm{CPB}$. As shown in Figure 4, the higher strength was obtained in the CPB for higher cement content. Some studies have pointed out that, according to the requirements of safe mining, the UCS of the CPB cured for 28 days for stope bottom filling should be greater than $2 \mathrm{MPa}$ [47]. When the cement/tailing ratio was 1:6, and the slurry concentration was $70 \%$, the strength of the CPB with a curing age of 28 days was $2.06 \mathrm{MPa}$, which could satisfy the requirements for stope bottom filling. In addition, this study also verified that the CPB slurry with a mass concentration of $70 \%$ could be conveyed to the stope through gravity or pumping.

\subsection{Environmental Effects of the Backfill Slurry}

The LZT contains many heavy metal elements, and its threat to the environment has attracted continuous social attention. This study monitored the metal leaching behaviour of backfill slurry and found that the leaching concentration of lead gradually became steady after $30 \mathrm{~h}$ and still exceeded the Chinese standard for groundwater quality (Class III) [43]. However, as shown in Figure 6 and Table 5, due to the hydration process of the cement, most of the metal elements in the backfill slurry were well stabilised. Therefore, pollutants in LZT could be converted into insoluble or slightly soluble materials by incorporating cementitious materials, which make it less harmful.

\subsection{Strength Change and Environmental Stability of CPB after Adding Immobilisation Materials}

Because aluminium sulfate accelerates the hydration of tricalcium silicate $\left(C_{3} S\right)$, the UCS of the $\mathrm{CPB}$ was slightly improved after the addition of PAS. Meanwhile, the hydrolysate of PAS resulted in the coagulation and precipitation of lead. After $24 \mathrm{~h}$ of pre-setting, the concentration of lead in 
the bleeding slurry was less than the GB standard when the dosage of PAS was $2 \mathrm{mg} / \mathrm{L}$. As shown in Figures 8-10, and Table 7, if LZT was directly discharged without treatment, the metals in LZT would diffuse with leachate, which could cause serious ecological damage to the surrounding areas. Compared with the metal concentration leached by LZT, the leaching concentration of lead, zinc, iron, chromium, arsenic, copper, and nickel in the $\mathrm{CPB}$ all met the national standard and had excellent environmental stability.

\section{Conclusions}

The total amount of lead-zinc tailings produced in China is huge each year. The recycling of LZT for the stope filling can ensure the sustainable development of lead-zinc mining, which is of great significance. This study evaluated the feasibility of recycling lead-zinc tailings for CPB. The mechanical performance of the $\mathrm{CPB}$ was related to the slurry concentration and cement/tailing ratio. The UCS test results showed that LZT-based CPB could be a safe alternative for massive consumption of LZT. Moreover, this study concluded that the addition of $2 \mathrm{mg} / \mathrm{L}$ PAS could effectively control the leaching of lead in the $\mathrm{CPB}$. All monitored metals satisfied the Chinese standard for groundwater quality (Class III) [43] in the dynamic leaching test, indicating that the technology of recovering LZT as the $\mathrm{CPB}$ proposed in this study was an effective method of alleviation of LZT pollution. Although over $14 \%$ of the binder was used in the present study, which might be attributed to a high proportion of fine particles in LZT, and the LZT was gap-graded aggregate, the technology improved the overall efficiency of the mine and brought great environmental benefits. This study also suggested that further research should focus on the development of effective and economical binders for the LZT-based CPB.

Author Contributions: Formal analysis, Z.S. and D.Z.; writing—original draft preparation, Z.S.; supervision, Q.C. and D.Z.; project administration, Q.Z.

Funding: This research is supported by the Fundamental Research Funds for the Central Universities of Central South University (2019zzts989).

Conflicts of Interest: The authors declare no conflict of interest.

\section{References}

1. Tao, M.; Zhang, X.; Wang, S.; Cao, W.; Jiang, Y. Life cycle assessment on lead-zinc ore mining and beneficiation in China. J. Clean. Prod. 2019, 237, 117833. [CrossRef]

2. Chen, Y.; Jiang, X.; Wang, Y.; Zhuang, D. Spatial characteristics of heavy metal pollution and the potential ecological risk of a typical mining area: A case study in China. Process Saf. Environ. Prot. 2018, 113, $204-219$. [CrossRef]

3. Ye, M.; Li, G.; Yan, P.; Ren, J.; Zheng, L.; Han, D.; Sun, S.; Huang, S.; Zhong, Y. Removal of metals from lead-zinc mine tailings using bioleaching and followed by sulfide precipitation. Chemosphere 2017, 185, 1189-1196. [CrossRef] [PubMed]

4. Wang, X.; Yu, R.; Shui, Z.; Zhao, Z.; Song, Q.; Yang, B.; Fan, D. Development of a novel cleaner construction product: Ultra-high performance concrete incorporating lead-zinc tailings. J. Clean. Prod. 2018, 196, 172-182. [CrossRef]

5. He, Y.; Chen, Q.; Qi, C.; Zhang, Q.; Xiao, C. Lithium slag and fly ash-based binder for cemented fine tailings backfill. J. Environ. Manag. 2019, 248, 109282. [CrossRef]

6. Zhang, J.; Li, M.; Taheri, A.; Zhang, W.; Wu, Z.; Song, W. Properties and Application of Backfill Materials in Coal Mines in China. Minerals 2019, 9, 53. [CrossRef]

7. Liu, H.; Zhang, J.; Zhang, W.; Gao, F.; Yan, H.; An, T. Experimental Investigation of Perceptual Characteristics of Functional Cemented Backfilling Materials in Coal Mines. Minerals 2019, 9, 55. [CrossRef]

8. Yin, Y.; Zhao, T.; Zhang, Y.; Tan, Y.; Qiu, Y.; Taheri, A.; Jing, Y. An Innovative Method for Placement of Gangue Backfilling Material in Steep Underground Coal Mines. Minerals 2019, 9, 107. [CrossRef]

9. Xu, W.; Cao, P.; Tian, M. Strength Development and Microstructure Evolution of Cemented Tailings Backfill Containing Different Binder Types and Contents. Minerals 2018, 8, 167. [CrossRef] 
10. Lv, W.; Wu, Y.; Ming, L.; Yin, J. Migration Law of the Roof of a Composited Backfilling Longwall Face in a Steeply Dipping Coal Seam. Minerals 2019, 9, 188. [CrossRef]

11. Béket Dalcé, J.; Li, L.; Yang, P. Experimental Study of Uniaxial Compressive Strength (UCS) Distribution of Hydraulic Backfill Associated with Segregation. Minerals 2019, 9, 147. [CrossRef]

12. Zhou, N.; Ma, H.; Ouyang, S.; Germain, D.; Hou, T. Influential Factors in Transportation and Mechanical Properties of Aeolian Sand-Based Cemented Filling Material. Minerals 2019, 9, 116. [CrossRef]

13. Zhang, P.; Zhang, Y.; Zhao, T.; Tan, Y.; Yu, F. Experimental Research on Deformation Characteristics of Waste-Rock Material in Underground Backfill Mining. Minerals 2019, 9, 102. [CrossRef]

14. Taheri, A.; Tatsuoka, F. Small-and large-strain behaviour of a cement-treated soil during various loading histories and testing conditions. Acta Geotech. 2015, 10, 131-155. [CrossRef]

15. Taheri, A.; Tatsuoka, F. Stress-strain relations of cement-mixed gravelly soil from multiple-step triaxial compression test results. Soils Found. 2012, 52, 748-766. [CrossRef]

16. Gao, W.; Ni, W.; Zhang, Y.; Li, Y.; Shi, T.; Li, Z. Investigation into the semi-dynamic leaching characteristics of arsenic and antimony from solidified/stabilized tailings using metallurgical slag-based binders. J. Hazard. Mater. 2020, 381, 120992. [CrossRef]

17. Zhang, J.; Deng, H.; Taheri, A.; Deng, J.; Ke, B. Effects of Superplasticizer on the Hydration, Consistency, and Strength Development of Cemented Paste Backfill. Minerals 2018, 8, 381. [CrossRef]

18. Zhao, Y.; Soltani, A.; Taheri, A.; Karakus, M.; Deng, A. Application of Slag-Cement and Fly Ash for Strength Development in Cemented Paste Backfills. Minerals 2019, 9, 22. [CrossRef]

19. Fellet, G.; Marchiol, L.; Vedove, G.; Peressotti, A. Application of biochar on mine tailings: Effects and perspectives for land reclamation. Chemosphere 2011, 83, 1262-1267. [CrossRef]

20. Mudd, G.; Jowitt, S.; Werner, T. The world's lead-zinc mineral resources: Scarcity, data, issues and opportunities. Ore Geol. Rev. 2017, 80, 1160-1190. [CrossRef]

21. Tang, C.; Chen, Y.; Zhang, Q.; Li, J.; Zhang, F.; Liu, Z. Effects of peat on plant growth and lead and zinc phytostabilization from lead-zinc mine tailing in southern China: Screening plant species resisting and accumulating metals. Ecotoxicol. Environ. Saf. 2019, 176, 42-49. [CrossRef] [PubMed]

22. Chen, Q.; Zhang, Q.; Qi, C.; Fourie, A.; Xiao, C. Recycling phosphogypsum and construction demolition waste for cemented paste backfill and its environmental impact. J. Clean. Prod. 2018, 186, 418-429. [CrossRef]

23. Deng, D.; Liu, L.; Yao, Z.; Song, K.; Lao, D. A practice of ultra-fine tailings disposal as filling material in a gold mine. J. Environ. Manag. 2017, 196, 100-109. [CrossRef] [PubMed]

24. Chen, Q.; Zhang, Q.; Fourie, A.; Chen, X.; Qi, C. Experimental investigation on the strength characteristics of cement paste backfill in a similar stope model and its mechanism. Constr. Build. Mater. 2017, 154, $34-43$. [CrossRef]

25. Shi, X.; Zhao, J.; Yin, J.; Yu, Z. An elastoplastic model for gap-graded soils based on homogenization theory. Int. J. Solids Struct. 2019, 163, 10-14. [CrossRef]

26. Chen, X.; Shi, X.; Zhou, J.; Du, X.; Chen, Q.; Qiu, X. Effect of overflow tailings properties on cemented paste backfill. J. Environ. Manag. 2019, 235, 133-144. [CrossRef]

27. Common Portland Cement; GB175-2007; Standardization Administration of China: Beijing, China, 2007.

28. Chen, Q.; Zhang, Q.; Fourie, A.; Xin, C. Utilization of phosphogypsum and phosphate tailings for cemented paste backfill. J. Environ. Manag. 2017, 201, 19. [CrossRef]

29. Liu, Y.; Zhang, Q.; Chen, Q.; Qi, C.; Su, Z.; Huang, Z. Utilisation of water-washing pre-treated phosphogypsum for cemented paste backfill. Minerals. 2019, 9, 175. [CrossRef]

30. Chen, Q.; Zhang, Q.; Wang, X.; Xiao, C.; Hu, Q. A hydraulic gradient model of paste-like crude tailings backfill slurry transported by a pipeline system. Environ. Earth. Sci. 2016, 75, 1099. [CrossRef]

31. Qi, C.; Fourie, A.; Chen, Q. Neural network and particle swarm optimization for predicting the unconfined compressive strength of cemented paste backfill. Construct. Build. Mater. 2018, 159, 473-478. [CrossRef]

32. IAEA. Underground Disposal of Radioactive Wastes: Basic Guidelines Safety Series No. 54; IAEA: Vienna, Austria, 1981.

33. Vaghela, P. Radioactive waste treatment and disposal techniques. Chem. Prod. Finder 2000, 18, $102-111$.

34. Rout, T.; Sengupta, D.; Kaur, G.; Kumar, S. Enhanced removal of dissolved metal ions in radioactive effluents by flocculation. Int. J. Miner. Process. 2006, 80, 215-222. [CrossRef] 
35. Freitas, J.; Santana, K.; Nascimento, A.; Paiva, S.; Moura, M.; Coelho, L.; Oliveira, M.; Paiva, P.; Nascimento, A.; Napoleão, T. Evaluation of using aluminum sulfate and water-soluble Moringa oleifera seed lectin to reduce turbidity and toxicity of polluted stream water. Chemosphere 2016, 163, 133-141. [CrossRef] [PubMed]

36. Yuan, Y.; Chai, L.; Yang, Z.; Liao, Y.; Deng, X.; Zhang, S. Application of polymeric aluminum salts in remediation of soil contaminated by $\mathrm{Pb}, \mathrm{Cd}, \mathrm{Cu}$, and Zn. J. Cent. South Univ. 2013, 20, 1638-1644. [CrossRef]

37. Chapter Seven of the SW-846 Compendium: Introductory and Regulatory Definitions Pertaining to Hazardous Waste Characteristics; EPA: Washington, DC, USA, 2004.

38. Lu, C.; Hsu, M.; Lin, Y. Evaluation of heavy metal leachability of incinerating recycled aggregate and solidification/stabilization products for construction reuse using TCLP, multi-final $\mathrm{pH}$ and EDTA-mediated TCLP leaching tests. J. Hazard. Mater. 2019, 368, 336-344. [CrossRef]

39. Wang, H.; Chen, K. A study of the engineering properties of CLSM with a new type of slag. Constr. Build. Mater. 2016, 102, 422-427. [CrossRef]

40. Yilmaz, T.; Ercikdi, B. Predicting the uniaxial compressive strength of cemented paste backfill from ultrasonic pulse velocity test. Nondestr. Test. Eval. 2016, 31, 247-266. [CrossRef]

41. Khaldoun, A.; Ouadif, L.; Baba, K.; Bahi, L. Valorization of mining waste and tailings through paste backfilling solution, imiter operation, Morocco. Int. J. Miner. Sci. Technol. 2016, 26, 511-516. [CrossRef]

42. Wu, D.; Zhang, Y.; Liu, Y. Mechanical performance and ultrasonic properties of cemented gangue backfill with admixture of fly ash. Ultrasonics 2016, 64, 89-96. [CrossRef]

43. Standard for Ground Water; GB14848-2017; Standardization Administration of China: Beijing, China, 2017.

44. Huang, H.; Zhang, P.; Yang, L.; Zhang, D.; Guo, G.; Liu, J. A pilot-scale investigation on the recovery of zinc and phosphate from phosphating wastewater by step precipitation and crystallization. Chem. Eng. J. 2017, 317, 640-650. [CrossRef]

45. Tan, H.; Li, M.; Ren, J.; Deng, X.; Zhang, X.; Nie, K.; Zhang, J.; Yu, Z. Effect of aluminum sulfate on the hydration of tricalcium silicate. Constr. Build. Mater. 2019, 205, 414-424. [CrossRef]

46. Li, X.; Du, J.; Gao, L.; He, S.; Gan, L.; Sun, C.; Shi, Y. Immobilization of phosphogypsum for cemented paste backfill and its environmental effect. J. Clean. Prod. 2017, 156, 137-146. [CrossRef]

47. Belem, T.; Benzaazoua, M. Design and application of underground mine paste backfill technology. Geotech. Geol. Eng. 2008, 26, 147-174. [CrossRef]

(C) 2019 by the authors. Licensee MDPI, Basel, Switzerland. This article is an open access article distributed under the terms and conditions of the Creative Commons Attribution (CC BY) license (http://creativecommons.org/licenses/by/4.0/). 